\title{
Multipl primer malign neoplaziler: Cumhuriyet Üniversitesi verileri
}

\author{
Multiple primary malignant neoplasms: Data of Cumhuriyet University \\ Nalan Akgül Babacan*, Saadettin Kılıçkap, Şafak Şahin, Birsen Yücel, Turgut \\ Kaçan, Ebru Atasever Akkaş, Yıllar Okur, Mehmet Fuat Eren
}

Tıbbi Onkoloji Bilim Dalı (Yrd. Doç. Dr. N. A. Babacan, Doç. Dr. S. Kılıçkap, Dr. T. Kaçan), Radyasyon Onkolojisi Anabilim Dalı (Yrd. Doç. Dr. B. Yucel, Dr. E. A. Akkaş, Yrd. Doç. Dr. Y. Okur, Yrd. Doç. Dr. M. F. Eren), Cumhuriyet Üniversitesi Tıp Fakültesi, 58140-Sivas; İç Hastalıkları Anabilim Dalı (Yrd. Doç. Dr. Ş. Şahin), Gaziosmanpaşa Üniversitesi Tıp Fakültesi, TR-60100 Tokat

\section{Özet}

Amaç. Onkolojik tedavilerdeki gelişmeler ve beklenen yaşam süresinin uzaması, tedavilerin geç yan etkileri ve ikinci kanserlerin gelişimi gibi sorunları da beraberinde getirmiştir. Aynı kişide, patolojik olarak tanımlanmış birden fazla malign tümörün varlığı multipl primer malign neoplazi (MPMN) olarak tanımlanmaktadır. Biz bu çalışmayla merkezimizde MPMN tanısı almış hastalarımızın demografik, patolojik ve klinik özelliklerini incelemeyi amaçladık. Yöntem. Merkezimize Ocak 2007 ile Ocak 2012 tarihleri arasında başvuran toplam 3108 kanser hastasına ait dosya bilgileri retrospektif olarak tarand1. Bulgular. Merkezimizde takip edilen 3108 kanser hastasının 38'i (\%1,2) MPMN tanısı almış idi. Bunların 21'i (\%55,3) kadın, 17'si (\%44,7) erkekti. Otuz yedi hastada iki primer neoplazi saptanırken, 1 hastada 3 primer neoplazi saptandi. Hastaların ortanca ikinci tümör tanı yaşı 60 (32-76) bulundu. Hastaların 6'sı (\%15,8) senkron, 32'si (\%84,2) metakron olarak MPMN tanısı almıştı. İki tanı arası geçen ortanca süre 40 aydı (0-372 ay). Hastalardaki en sık ilk primer tümör jinekolojik tümörler (10 hasta, \%26,3) iken, en sık ikinci primer tümör meme kanseri $(7$ hasta, \%18,4) idi. En sık tümör birliktelikleri ise sırasıly: jinekolojik tümörler-meme kanseri (5 hasta, \%13,1), jinekolojik-jinekolojik tümörler (3 hasta, \%7,9), sarkom-meme kanseri (3 hasta, \%7,9), baş boyun tümörleri-akciğer kanseri (3 hasta, \%7,9), üriner sistem-üriner sistem tümörleri (3 hasta, \%7,9) şeklindeydi. Sonuçlar. Sonuçlarımız literatürr ile uyumludur. Kanser tanısı almış hastalar, olası ikinci kanserler, koruyucu önlemler ve tarama hakkında bilgilendirilmeli ve şüpheli lezyonlarda biyopsiden kaçınılmamalıdır.

Anahtar sözcükler: Kanser, ikinci primer neoplasm, multipl neoplaziler, metakron, senkron

\begin{abstract}
Aim. Developments in cancer treatment and longer anticipated life period have brought out late side effects related to therapy and development of a second cancer. Multiple primary malignant neoplasms (MPMN) are described as pathological diagnosis of two or more independent primary reportable neoplasms in an individual. In this study we aimed to investigate demographic, pathological and clinical features of patients with multiple primary cancers in our center. Method. From January 2007 to January 2012, medical files of totally 3108 cancer patients were retrospectively screened. Results. Thirty-eight (1.2\%) of 3108 cancer patients followed-up at our centre were diagnosed as MPMN. Of these patients, $21(55.3 \%)$ was female, and $17(45 \%)$ was male. While 37 patients were found to have two different primary malignant neoplasms, only one patient had three different primary cancers. The median age at the initial time of second primary cancer was 60 years (32-76). Patients with MPMN were diagnosed as synchronous neoplasm in six patients $(16 \%)$ and as metachronous neoplasm in thirty-two (84\%) patients. The median interval between the first and second cancers was 40 months (0-372). The most common primary tumor was gynecological cancers $(n=10 ; 26 \%)$ and the most common secondary cancer was breast cancer $(\mathrm{n}=7 ; 18 \%)$. The most common cancer couplings were gynecological-breast cancer $(\mathrm{n}=5$; $13 \%)$, gynecological- gynecological cancer $(n=3 ; 8 \%)$, sarcoma-breast cancer $(n=3 ; 8 \%)$, head and neck-lung cancer $(n=3 ; 8 \%)$, and urinary-urinary system cancer $(n=3 ; \% 8)$, respectively. Conclusion. Our results comply with the literature. Patients with cancer should be informed by physicians about development of secondary neoplasm, cancer prevention and screening. Clinicians should not hesitate from biopsy in suspected lesions.
\end{abstract}

Keywords: Cancer, second primary neoplasm, multiple neoplasms, metachronous, synchronous 
Geliş tarihi/Received: 01 Mart 2012; Kabul tarihi/Accepted: 11 Eylül 2012

\section{*İletişim adresi:}

Dr. Nalan Akgül Babacan, Tıbbi Onkoloji Bilim Dalı, Cumhuriyet Üniversitesi Tıp Fakültesi, 58140-Sivas. E-posta: nalan.a@mynet.com

\section{Giriş}

Onkolojik tedavilerdeki gelişmeler ve beklenen yaşam süresinin uzaması, tedavilerin geç yan etkileri ve ikinci kanserlerin gelişimi gibi sorunları da beraberinde getirmiştir. Aynı kişide, patolojik olarak tanılanmış birden fazla malign tümörün varlığı multipl primer malign neoplazi (MPMN) olarak tanımlanmaktadır. MPMN ilk kez 1889'da Billroth tarafindan tanımlanmış ve ilk literatür verisi 1932'de Warren ve Gates tarafından yayınlanmıştır [1]. Bu yazarların tanımına göre MPMN diyebilmek için, hem ilk (indeks) hem de ikinci tümörün histopatolojik değerlendirmesi olmalı, iki tümör arasında en az 2 $\mathrm{cm}$ normal mukoza bulunmalı ve metastaz ekarte edilmiş olmalıdır. Gelişim zamanına göre ikinci tümör ilk 6 ay içinde gelişmişse senkron; daha sonra gelişmişse metakron olarak adlandırılmaktadır [2]. MPMN sıklığı çeşitli yayınlara göre \%0,7 ile $\% 11,7$ arasında değişmektedir [3-7]. MPMN'nin olası sebeplerine bakıldığında genetik ve çevresel faktörlerin yanı sıra onkolojik tedavilerin (radyoterapi, kemoterapi) de yer aldığı görülmektedir [8-10]. Kemoterapötikler arasında alkilleyici ajanlar, antrasiklinler ve topoizomeraz II inhibitörlerinin ikinci kanserlere neden olabildikleri bilinmektedir [1118]. Bu ikinci kanserler genellikle akut lösemi şeklinde olup, kemoterapötiklere bağlı gelişen solid organ tümörlerine ait bilgi azdır. Çevresel nedenler arasında sigara ve alkol kullanımı başta gelmektedir.

Biz de merkezimizde MPMN tanısı almış hastalarımızın demografik, patolojik ve klinik özelliklerini incelemeyi planladık.

\section{Gereç ve yöntem}

Cumhuriyet Üniversitesi Onkoloji Merkezi'ne Ocak 2007 ile Ocak 2012 tarihleri arasında başvuran toplam 3108 hastaya ait dosya bilgileri tarandı ve MPMN tanısı olan 38 hastanın demografik verileri, klinik özellikleri ve sağ kalım verileri değerlendirildi.

Hastaların demografik ve klinik özellikleri tanımlayıcı analiz ile incelendi. İki grup arasındaki sayısal değişkenler Mann-Whitney $U$ veya $T$ test ile değerlendirildi. Gruplar arasındaki oranları kıyaslamak için de $\mathrm{X}^{2}$ testi kullanıldı. Tüm istatistiksel analizler Package for Social Sciences (SPSS v 15.0, SPSS Inc., Chicago, IL, USA) ile yapıldı ve $\mathrm{p}<0,05$ anlamlılık sinırı olarak kabul edildi.

Beş yıllık hasta verileri incelendiğinde 3108 kanser tanısıyla izlenen hastanın 38'inin $(\% 1,2)$ MPMN tanısı aldığ görüldü. Bunların 21'i $(\% 55,3)$ kadın, 17'si $(\% 44,7)$ erkekti, erkek/kadın oranı ise $0,72 \mathrm{idi}$. Otuz yedi hastada iki, 1 hastada ise 3 primer neoplazi saptanmıştı. Kadın hastaların ortanca ilk tanı yaşı 50 (13-70), erkeklerin ise 58 (39-76) olmakla beraber fark istatistiksel olarak anlamlı değildi. Hastaların ortanca ikinci tümör tanı yaşı 60 (32-76) bulundu. Hastaların 6's1 (\%15,8) senkron, 32'si (\%84,2) metakron olarak MPMN tanısı almıştı. İki tanı arası geçen ortanca süre 40 aydı (0-372 ay). Hastaların 17'si $(\% 44,7)$ sigara içiyordu ve bu grupta ortanca 35 paket/y1l (2-86) sigara kullanım öyküsü mevcuttu.

Dört hastada ailede kanser öyküsü mevcuttu: babasında akciğer, amcasında mide kanseri öyküsü olan bir hastamızda mesane-mide kanseri; babasında akciğer, annesinde meme ve ablasında over kanseri öyküsü bulunan hastamızda over-meme kanseri birlikteliği; annesinde meme kanseri öyküsü olan bir hastada endometrium-over ve babasında akciğer kanseri öyküsü olan bir hastamızda meme-over kanseri birlikteliği gözlendi. 
Tüm hastalar değerlendirildiğinde en sık 1. kanser jinekolojik tümörler (10 hasta, \%26,3), en s1k 2. kanser ise meme kanseri $(7$ hasta, \%18,4) idi. En s1k tümör birliktelikleri ise sırayla: jinekolojik tümörler-meme kanseri (5 hasta, \%13,1), jinekolojik-jinekolojik tümörler (3 hasta, \%7,9), sarkom-meme kanseri (3 hasta, \%7,9), baş boyun tümörleriakciğer kanseri (3 hasta, \%7,9), üriner sistem-üriner sistem tümörleri (3 hasta, \%7,9) şeklindeydi (Tablo 1).

Tablo 1. Tüm hastalara ait veriler.

\begin{tabular}{llll}
\hline Tüm hastalar & Tümör & Hasta sayısı & \% \\
\hline En sık 1. tümörler & Jinekolojik tümörler & 10 & 26,3 \\
En sık 2. tümörler & Meme ca & 7 & 18,4 \\
En sık tümör çiftleri & Jinekolojik- meme ca & 5 & 13,1 \\
& Jinekolojik-Jinekolojik & 3 & 7,9 \\
& Baş boyun-akciğer ca & 3 & 7,9 \\
& Sarkom-meme ca & 3 & 7,9 \\
\hline
\end{tabular}

Kadın hastalarda en sık 1. kanserler sırasıyla: jinekolojik tümörler (10 hasta, \%47,6) ve meme kanseri (3 hasta, \%14,3) iken, en s1k 2. kanserler: meme kanseri (7 hasta, \%33,3) ve jinekolojik tümörler ( 5 hasta, $\% 23,8$ ) olarak tespit edildi. Kadınlardaki en sık görülen tümör çiftleri jinekolojik tümörler-meme kanseri (5 hasta, \%23,8), Jineklojik-jinekolojik tümörler (3 hasta, \%14,3), sarkoma-meme kanseri (3 hasta, \%14,3) idi (Tablo 2).

Tablo 2. Kadın hasta verileri.

\begin{tabular}{llll}
\hline Kadın hastalar & Tümör & Hasta sayısı & \% \\
\hline En sık 1. tümörler & Jinekolojik tümörler & 10 & 47,6 \\
& Meme kanseri & 3 & 14,3 \\
\hline En sık 2. tümörler & Meme kanseri & 7 & 33,3 \\
& Jinekolojik tümörler & 5 & 23,8 \\
\hline En sık tümör çiftleri & Jinekolojik- meme kanseri & 5 & 23,8 \\
& Jineklojik-jinekolojik & 3 & 14,3 \\
& Sarkom-meme kanseri & 3 & 14,3 \\
\hline
\end{tabular}

Erkek hastalarda en sik 1. kanserler sirasıyla: üriner sistem tümörleri (5 hasta, \%29,4), baş-boyun tümörleri (4 hasta, \%23,6) iken en s1k 2. kanserler: akciğer kanseri (5 hasta, $\% 29,4)$ ve üriner sistem tümörleri (4 hasta, \%23,6) olarak tespit edildi. Erkeklerdeki en sık tümör çiftleri ise, baş boyun tümörleri-akciğer kanseri (3 hasta, \%17,6) ve üriner sistem tümörleri-üriner sistem tümörleri (3 hasta, \% 17,6) idi (Tablo 3).

Tablo 3. Erkek hasta verileri.

\begin{tabular}{llll}
\hline Erkek hastalar & Tümör & Hasta sayısı & \% \\
\hline En sık 1. tümörler & Üriner sistem tm & 5 & 29,4 \\
& Baş-boyun tm & 4 & 23,6 \\
\hline \multirow{2}{*}{ En sık 2. tümörler } & Akciğer & 5 & 29,4 \\
& Üriner sistem & 4 & 23,6 \\
\hline \multirow{2}{*}{ En sık tümör çiftleri } & Baş boyun tm- akciğer & 3 & 17,6 \\
& Üriner sist-üriner sistem & 3 & 17,6 \\
\hline
\end{tabular}

Hastaların takipleri boyunca 33'ü $(\% 86,8)$ kemoterapi, 22'si $(\% 57,9)$ radyoterapi, 5'i $(\% 13,2)$ hormonal tedavi almış, ilk tümörleri nedeniyle 35 hastaya $(\% 92,1)$, ikinci tümörleri nedeniyle de 23 hastaya $(\% 60,5)$ cerrahi tedavi uygulanmıştı. Ortanca 66 (1380) aylık takip sürecinde 10 hastanın (\%26) ölüm bilgisine ulaşıldı, ancak ortanca sağkalım verisine ulaşılamamakla birlikte 5 yıllık sağkalım \%93 olarak hesaplandı.

\section{Tartışma}

Erken tanı ve tedavideki olumlu gelişmeler sayesinde, kanserli hastalarda beklenen yaşam süresi artmıştır [19]. Bu nedenle onkoloji pratiğinde ikinci kanserlerin önemi giderek artmaktadir. 
MPMN sıklığ yayınlara göre \%0,7 ile \%11,7 arasında değişmektedir [3-7]. Bizim 5 yıllık hasta verilerimize göre de bu oran \%1,2'dir ve literatür verileri ile uyumludur. İkinci maligniteler genellikle ileri yaşta görülür ve yayınlara göre hastaların $>\% 75$ 'i elli yaşın üzerindedir [7, 20,21]. Çalışmamızdaki hastaların da ortanca 2. kanser tanı yaşı 60 (3276) bulunmuş olup, literatürle uyumludur. MPMN tanılı hastalarda erkek/kadın oranı çeşitli yayınlarda 0,9 ile 3,5 arasında değişmektedir $[6,7,22,23]$. Bizim çalışmamızda ise erkek/kadın oranı 0.72 olup kadın cinsi lehine bulunmuştur.

Multipl primer neoplazi için önemli bir ortak etiyolojik faktör olan sigara içime sıklığ yayınlarda \%49 ile \%64 arasında değişmekle birlikte [20, 24] ve bu oran çalışmamızda \%45 bulunmuştur. Sigara kullanımı başta akciğer kanseri olmak üzere, baş-boyun, özefagus, pankreas, üriner sistem ve serviks kanserinin etiyolojisinde rol almaktadır [810]. 'Saha kanserizasyon' teorisine göre sigara, alkol gibi karsinojenler belli organlarda kansere yol açabildikleri gibi aynı etkiye maruz kalan diğer mukozalarda da (solunumsindirim sistemi hattı ve ürotelyal epitelyum gibi) ikinci bir kanseri de başlatabilirler [25]. Ayrıca sigaraya devam etmenin ikinci kanser sıklığını artırırken, sigarayı bırakmanın bu riski azalttığ 1 bilinmektedir [26-28].

Genetik faktörler de MPMN'nin sebeplerinden biri olmakla beraber, ailesel yatkınlık, ikinci kanserlerin küçük bir oranından sorumludur. Bunlardan başlıcaları BRCA gen mutasyonu ilişkili kanserler (artmış meme, kolon, over kanseri riski), herediter nonpolipozis kolorektal kanser sendromları (artmış gastrointestinal sistem, over ve endometriyum kanserleri riski) ve Li Fraumeni sendromudur (artmış meme kanseri, sarkoma, beyin tümörü, lösemi ve adrenal tümör riski) [29]. Çalışmamızdaki hastalardan ailede kanser öyküsü olan hastalarda meme-jinekolojik kanserlerin görülmesi dikkat çekicidir ve bu hastalar BRCA mutasyonu yönünden değerlendirilmelidir.

MPMN hastaları genellikle metakron olarak tanı almaktadırlar. Aydıner ve ark. [7]'nın serisinde metakron tanı alan MPMN oranı \%66 iken bizim çalışmamızda bu oran \%84 ve iki tanı arasında geçen ortanca süre 40 (0-372) ay bulunmuştur.

Amerikan SEER (Surveillance, Epidemiology, and Results) verilerine göre MPMN tanılı hastalarda en sik indeks tümör prostat kanseri iken, bizde en sı jinekolojik tümörler saptanmıştır. $\mathrm{Bu}$ farkın nedeni prostat kanserli vakaların önemli bir bölümünün üroloji kliniklerince takip edilmesi ve merkezimize sadece metastatik olguların başvurması olabilir. Ülkemizden bildirilen MPMN serilerinde en sık gözlenen tümörler larinks, akciğer ve meme kanseri olarak bildirilmektedir [7, 20,30].

SEER verilerine göre erkeklerdeki en sık tümör çiftleri (indeks tümör-ikinci tümör) prostat-akciğer \& solunum sistemi kanserleri, ikinci olarak prostat-kolon kanseridir. Kadınlarda ilk iki sırayı, meme kanseri-meme kanseri, ikinci olarak da meme kanserikolon kanseri çiftleri almıştır [31]. Bizim verilerimizde ise erkeklerde baş-boyun tümörleri-akciğer kanseri, üriner sistem-üriner sistem kanserleri en sik saptananan tümör çiftleri iken; kadınlarda jinekolojik kanserler-meme kanseri ve jinekolojik-jinekolojik kanser en sık görülen tümör çiftlerini oluşturmaktaydı.

Sonuç olarak, kanser tanısı almış hastalar ikinci kanser riski açısından dikkatle izlenmelidir. Ayrıca hastalar, koruyucu önlemler (alkol, sigara kullanımını kesme, UV 1şınlarından sakınma, gibi), tarama programları (mamografi, servikal smear, gaitada gizli kan aranması vs) hakkında bilgilendirilmeli ve yaşam şekli değişiklikleri konusunda yüreklendirilmelidir.

\section{Kaynaklar}

1. Warren S, Gates O. Multiple primary malignant tumors: A survey of the literature and a statistical study. Am J Cancer 1932; 16: 1358-414.

2. Vaamonde P, Martín C, del Río M, LaBella T. Second primary malignancies in patients with cancer of the head and neck. Otolaryngol Head Neck Surg 2003; 129: 65-70. 
3. Spratt JS Jr, Hoag MG. Incidence of multiple primary cancers per man-year of follow up: 20-year review from the Ellis Fischel State Cancer Hospital. Ann Surg 1966; 164: 775-84.

4. Hajdu SI, Hajdu EO. Multiple primary malignant tumors. J Am Geriatr Soc 1968; 16: 16-26.

5. Berge T, Cederqvist L, Schönebeck J. Multiple primary malignant tumours. An autopsy study of a circumscribed population. Acta Pathol Microbiol Scand 1969; 76: $171-83$.

6. Lee TK, Myers RT, Scharyj M, Marshall RB. Multiple primary malignant tumors (MPMT): study of 68 autopsy cases (1963-1980). J Am Geriatr Soc 1982; 30: 744-53.

7. Aydıner A, Karadeniz A, Uygun K, Tas S, Tas F, Disci R, Topuz E. Multiple primary neoplasms at a single institution: differences between synchronous and metachronous neoplasms. Am J Clin Oncol 2000; 23: 364-70.

8. Office on Smoking and Health, a, Report of the Surgeon General. DHEW Publ No (PHS)79-50066. Washington D, U.S. Government, Printing Office; 1979.

9. Brinton LA, Blot WJ, Becker JA, Winn DM, Browder JP, Farmer JC Jr, Fraumeni JF Jr. A case-control study of cancers of the nasal cavity and paranasal sinuses. Am J Epidemiol 1984; 119: 896-906.

10. Kelsey JL, Hildreth NG. Breast and gynecology cancer epidemiology. Boca Raton, FL, CRC Press, Inc 1983.

11. Saso R, Kulkarni S, Mitchell P, Treleaven J, Swansbury GJ, Mehta J, Powles R, Ashley S, Kuan A, Powles T. Secondary myelodysplastic syndrome/acute myeloid leukaemia following mitoxantrone-based therapy for breast carcinoma. Br J Cancer 2000; 83: 91-4.

12. Chaplain G, Milan C, Sgro C, Carli PM, Bonithon-Kopp C. Increased risk of acute leukemia after adjuvant chemotherapy for breast cancer: a population-based study. J Clin Oncol 2000; 18: 2836-42.

13. Beaumont M, Sanz M, Carli PM, Maloisel F, Thomas X, Detourmignies L, Guerci A, Gratecos N, Rayon C, San Miguel J, Odriozola J, Cahn JY, Huguet F, Vekhof A, Stamatoulas A, Dombret H, Capote F, Esteve J, Stoppa AM, Fenaux P. Therapy-related acute promyelocytic leukemia. J Clin Oncol 2003; 21: 212337.

14. van Leeuwen FE, Chorus AM, van den Belt-Dusebout AW, Hagenbeek A, Noyon R, van Kerkhoff EH, Pinedo HM, Somers R. Leukemia risk following Hodgkin's disease: relation to cumulative dose of alkylating agents, treatment with teniposide combinations, number of episodes of chemotherapy, and bone marrow damage. J Clin Oncol 1994; 12: 1063-73.

15. van Leeuwen FE, Klokman WJ, Veer MB, Hagenbeek A, Krol AD, Vetter UA, Schaapveld M, van Heerde P, Burgers JM, Somers R, Aleman BM. Long-term risk of second malignancy in survivors of Hodgkin's disease treated during adolescence or young adulthood. J Clin Oncol 2000; 18: 487-97.

16. Kaldor JM, Day NE, Pettersson F, Clarke EA, Pedersen D, Mehnert W, Bell J, Høst H, Prior P, Karjalainen S, Neal F, Koch M, Band P, Choi W, Kirn VP, Arslan A, Zarén M, Belch AR, Storm H, Kittelmann B, Fraser P, Stovall M. Leukemia following chemotherapy for ovarian cancer. N Engl J Med 1990; 322: $1-6$.

17. Curtis RE, Boice JD Jr, Stovall M, Bernstein L, Greenberg RS, Flannery JT, Schwartz AG, Weyer P, Moloney WC, Hoover RN. Risk of leukemia after chemotherapy and radiation treatment for breast cancer. N Engl J Med 1992; 326: 1745-51.

18. Swerdlow AJ, Barber JA, Hudson GV, Cunningham D, Gupta RK, Hancock BW, Horwich A, Lister TA, Linch DC. Risk of second malignancy after Hodgkin's disease in a collaborative British cohort: the relation to age at treatment. J Clin Oncol 2000; 18: 498-509. 
19. Ries LAG, Harkins D, Krapcho M, Mariotto A, Miller BA, Feuer EJ, Clegg L, Eisner MP, Horner MJ, Howlader N, Hayat M, Hankey BF, Edwards BK (eds). SEER Cancer Statistics Review, 1975-2003, National Cancer Institute. Bethesda, MD, http://seer.cancer.gov/csr/1975_2003 (Erişim tarihi 06 Aralık 2012).

20. Gursel B, Meydan D, Özbek N, Ozdemir O, Odabas E. Multiple Primary Malignant Neoplasms from the Black Sea Region of Turkey. J Int Med Res 2011; 39: 667-74.

21. Demandante CG, Troyer DA, Miles TP. Multiple primary malignant neoplasms: case report and a comprehensive review of the literature. Am J Clin Oncol 2003; 26: 79-83.

22. Ueno M, Muto T, Oya M, Ota H, Azekura K, Yamaguchi T. Multiple primary cancer: an experience at the Cancer Institute Hospital with special reference to colorectal cancer. Int J Clin Oncol 2003; 8: 162-7.

23. Vyas JJ, Deshpande RK, Sharma S, Desai PB. Multiple primary cancers in Indian population: metachronous and synchronous lesions. J Surg Oncol 1983; 23: 23949.

24. Schwartz LH, Ozsahin M, Zhang GN, Touboul E, De Vataire F, Andolenko P, Lacau-Saint-Guily J, Laugier A, Schlienger M. Synchronous and metachronous head and neck carcinomas. Cancer 1994; 74:1933-8.

25. Slaughter DP, Southwick HW, Smejkal W. Field cancerization in oral stratified squamous epithelium; clinical implications of multicentric origin. Cancer 1953; 6: $963-8$.

26. Liu YY, Chen YM, Yen SH, Tsai CM, Perng RP. Multiple primary malignancies involving lung cancer-clinical characteristics and prognosis. Lung Cancer 2002; 35: 189-94.

27. Weichert KA, Schumrick D. Multiple malignancies in patients with primary carcinomas of the head and neck. Laryngoscope 1979; 89: 988-91.

28. Tucker MA, Murray N, Shaw EG, Ettinger DS, Mabry M, Huber MH, Feld R, Shepherd FA, Johnson DH, Grant SC, Aisner J, Johnson BE. Second primary cancers related to smoking and treatment of small-cell lung cancer. Lung Cancer Working Cadre. J Natl Cancer Inst 1997; 89: 1782-8.

29. DeVita VTL, Theodore S.; Rosenberg, Steven A.: Devita, Hellman \& Rosenberg's Cancer: Principles \& Practice of Oncology, 8th Edition edn. California; 2008.

30. Engin K. Cancers in multiple primary sites. Int Surg 1994; 79: 33-7.

31. Hayat MJ, Howlader N, Reichman ME, Edwards BK. Cancer statistics, trends, and multiple primary cancer analyses from the Surveillance, Epidemiology, and End Results (SEER) Program. Oncologist 2007; 12: 20-37. 